\title{
Teatro do Oprimido no Cariri - TOCA
}

Mateus Gonçalves - Universidade Regional do Cariri - mateus.goncalves@urca.br Anderson Fabrício Teixeira Soares - Universidade Regional do Cariri sr_teixeirinha@hotmail.com

Palavras-chave: Teatro do Oprimido, Comunidade, Pesquisa, Extensão, Pedagogia do Teatro

A linha de pesquisa Teatro do Oprimido no Cariri - TOCA, vinculada ao grupo de pesquisa Pedagogias do Teatro no Cariri - PETECA, do Departamento de Teatro da Universidade Regional do Cariri - URCA, investiga as possíveis contribuições do sistema do Teatro do Oprimido - TO, criado e desenvolvido pelo teatrólogo brasileiro Augusto Boal, junto a instituições, grupos e coletivos na região Cariri, desenvolvendo práticas artísticas e sociais a partir de estudos sobre o TO.

A metodologia da pesquisa inclui estudos teórico-práticos sobre o TO, com revisão bibliográfica e experimentação dos jogos e técnicas propostos por Augusto Boal, a partir das experiências em diferentes contextos, com diversos sujeitos sociais. Realizam-se encontros semanais com bolsistas, onde estudos e ações são planejados e executados, conforme diferentes focos de análise de cada agente envolvido.

Em nosso primeiro ano (2016) realizamos estudos teóricos sobre a biografia de Augusto Boal, bem como de obras basilares do TO, tais como "Teatro do oprimido e outras poéticas políticas” (1991), “Jogos para atores e não-atores” (1998) e “A Estética do Oprimido” (2009), entre outras. Como o TO busca desvelar e superar situações de opressão junto a comunidades e grupos socialmente vulneráveis, de modo a promover a reflexão crítica sobre suas realidades e possíveis ações político-artísticas, em 2017 partimos para a experimentação prática da metodologia estudada no ano anterior, com o estabelecimento de parcerias para essas ações, primeiramente junto à Penitenciária Industrial Regional do Cariri - PIRC, no município de Juazeiro do Norte/CE, através do Programa Projovem Urbano Prisional, onde o TOCA desenvolveu oficinas de Teatro do Oprimido junto aos internos daquela unidade prisional, uma vez por semana ao longo de um mês. No mesmo ano realizamos uma oficina de introdução ao TO numa parceria com a ouvidoria da Universidade Federal do Cariri - UFCA. Nossos encontros de formação ampliaram-se ainda em 2017 com o “TOCA Saberes”, proposta de formação que consiste no contato de nosso grupo de pesquisadores com outros estudiosos de áreas relacionadas com nossa temática. Recebemos a colaboração de professoras do Curso de Licenciatura em Artes Visuais de nossa Universidade, bem como de professores do próprio Curso de Licenciatura em Teatro. 
Através da Pró-Reitoria de Extensão da URCA, o TOCA também estabeleceu parceira com a Secretaria de Cultura e a Secretaria de Desenvolvimento de Juazeiro do Norte/CE, para a realização do projeto "Teatro na Comunidade", com oficinas de teatro a crianças e adolescentes atendidos pelos Centros de Referência em Assistência Social - CRAS. O objetivo das oficinas foi o desenvolvimento artístico, estético e social dos participantes, por meio de técnicas do TO, buscando identificar situações de opressão e sua superação. Em 2018 o projeto vem sendo desenvolvido no município de Crato/CE, numa parceria com a Secretaria de Segurança Pública Municipal do Crato para o desenvolvimento de oficinas de TO junto a crianças e adolescents em comunidades deste município.

A pesquisa tem se desenvolvido com a produção de artigos e a participação do TOCA em eventos acadêmicos por todo Brasil, ensejando a ampliação de nossa compreensão sobre o TO e o compartilhamento de experiências com outros pesquisadores. Mantemos um sítio eletrônico para facilitar a divulgação de nossas ações e estudos, facilitando nossa comunicação com as pessoas que têm interesses comuns aos nossos. Nossa metodologia de pesquisa caracteriza o TO como uma possibilidade de extensão universitária, entendendo que o conhecimento se constrói em parceria, compartilhamento e ação concreta da Universidade com sua comunidade.

Referências Bibliográficas:

BOAL, Augusto. A estética do oprimido. Rio de Janeiro: Garamond,2009.

BOAL, Augusto. Jogos para atores e não-atores. Rio de Janeiro: Civilização Brasileira, 1998.

BOAL, Augusto. Teatro do oprimido e outras poéticas políticas. Rio de Janeiro: Civilização Brasileira, 1991.

CONCÍLIO, Vicente. Teatro e prisão: dilemas da liberdade artística. São Paulo: Hucitec, 2008.

FICHE, Natália Ribeiro. Teatro na prisão: trajetórias individuais e perspectivas coletivas.

Dissertação de Mestrado, Rio de Janeiro: Universidade Federal do Estado do Rio de Janeiro, 2009.

POMPEO, Marcia. Ventoforte: no teatro em comunidade. Florianópolis: Letras Contemporâneas, 2015.

SANCTUM, Flavio. A estética de Boal - Odisséia dos sentidos. Rio de Janeiro: Multifoco, 2012. 